\title{
Thermal insulation of the tent's heat shield in cold and hot climates
}

\author{
Adam Ujma* and Jakub Jura \\ Czestochowa University of Technology, 42-200 Czestochowa, Poland
}

\begin{abstract}
Tent structures are used in many places around the world in both cold and hot climates. They are often used in crisis situations, natural disasters and various types of rescue operations. In order to assess the thermal conditions inside the tent, it is necessary to know the thermal insulation of its external envelopes. The thermal insulation of the cover also determines the selection of equipment for heating or air conditioning the tent. The article presents tests of thermal properties of a tent fabric and the value of the heat transfer coefficient of thermal protection of an pneumatic tent. The thermal insulation of the tent covering consists of two fabric layers separated by an air gap. The research was carried out on the assumption that the tent would be used in cold and hot climate conditions. The thermal conductivity of the material and the conditions of heat transfer on its surfaces were determined. The obtained measurement data were then used to determine the thermal parameters of the tent's thermal shield.
\end{abstract}

\section{Introduction}

Tents are used in many situations, often requiring quick construction of a temporary, closed room. Used in various extreme, cold climatic conditions [1]. Due to their simple structure, they serve as a temporary shelter for the poor, refugees or people affected by natural disasters [2]. In countries where there are tornadoes, earthquakes or other cataclysms, they often have to replace damaged buildings for some time. Tents are used in refugee camps. In the face of many military conflicts, persecution and climate change, it is imperative to provide decent shelter for refugees [3]. Vaccination against COVID-19 is currently carried out in tents and will also be used for such purposes in the past.

When tents are used in rescue operations, it is important to properly arrange the tents to create a safe emergency shelter [4].

It is very important that people staying in the tent have a sense of thermal comfort. This is primarily determined by the temperature and humidity in the tent. Therefore, it is necessary to conduct research and model the heat transfer through the fabric of the tent for different climatic conditions [5].

Tents used as temporary laboratories or treatment rooms require heating or cooling. To select heating or air-conditioning devices, it is required to obtain data on the thermal insulation of the tent walls. The paper presents the results of tests of thermal insulation of tent walls. Particular attention was paid to determining the thermal conductivity of the tent fabric

\footnotetext{
${ }^{*}$ Corresponding author: adam.ujma@pcz.pl
} 
and the thermal emissivity of its surface. The thermal insulation of a single layer of tent fabric and a tent wall consisting of a double fabric separated by an air layer was assessed. The test results were used to determine the resistance to heat transfer on the tent surfaces, the thermal resistance of the walls and the heat transfer coefficient of the tent walls.

They are also used as field offices, laboratories, etc. Due to the low thermal insulation of thin tent coatings, the temperature in these specific rooms often does not provide comfortable thermal conditions for their users. The problem was the rapid increase in internal temperature during intense sunlight and a rapid decrease with lowering external temperature [6]. This is due to the practically zero thermal capacity of the tent structure. Research is being conducted on the modification of the structure of materials [7] and the application of additional coatings and layers [8]. They are aimed at improving the conditions of the indoor microclimate. The conducted experiments show that e.g. by applying a reflective layer to the outer layer, the air temperature in a tent is significantly reduced $[9,10]$. Reflective insulations used in various construction solutions of building partitions also significantly improve their thermal insulation [11]. Modification of the construction of building partitions through the use of various materials in thermal insulation layers, translates into lower costs of heating or cooling rooms, while ensuring appropriate thermal comfort conditions for people staying in them [12].

Thermal analysis of architectural fabrics is based on a number of approximations and assumptions. The adopted calculation models are characterized by many simplifications. In many technical facilities where architectural fabrics are used, a high level of thermal performance is required. New applications of fabrics, incl. in tents, they are associated with climate change in the world, rising energy costs and the need to create comfortable conditions for use [13].

Theoretical models of air temperature changes in tent rooms are created. The thermal properties of the tent shell are an important factor influencing the thermal environment inside the tent. The above conclusions are important theoretical support and technical guidance for testing and improving the internal thermal environment of the tent [14].

In the event of earthquakes and other natural disasters, victims need basic help in the form of shelter. In such places, adequate energy efficiency of the refuge room must be ensured. In hot climates, these conditions are assessed on the basis of the OTTV energy consumption value (Overall Thermal Transfer Value). The thermal comfort parameters expressed by the PMV index (Predicted Mean Vote) are also tested [15].

The tests of thermal conditions in tents show that the temperature inside the tent is often too high for the design parameters. Therefore, a significant problem is the appropriate selection of the type and thickness of the layers of materials and tent coverings. It is necessary for the correct selection of the parameters of heating and ventilation systems. Therefore, a significant problem is to determine the actual value of the heat transfer coefficient of the rack-tent structure. The article [16] draws attention to the lack of a refined engineering calculation technique that would allow to determine heat losses in frame-tent structures.

\section{Basics and assumptions of research on the outer partitions of a pneumatic tent}

The research was carried out to determine the value of the heat transfer coefficient of the thermal covering of the pneumatic tent. Such data must be the basis for the selection of heating or cooling inside the tent, when determining the demand for heating or cooling capacity, devices for heating or cooling the air in the tent.

The tested tent is a pneumatic structure (Fig. 1). The load-bearing system is a skeleton structure with a frame of interconnected longitudinal and transverse inflatable sleeves. The 
lengths of the elements forming the structure arch from the base to the top are: $1950 \mathrm{~mm}$ $1800 \mathrm{~mm}-500 \mathrm{~mm}$. The frame is filled with one or two layers of tent fabric. According to the manufacturer's data, the weight of the tent fabric is approx. $310 \mathrm{~g} / \mathrm{m}^{2}$ and a thickness of 0.30 $-0.35 \mathrm{~mm}$. The inside of the tent consists of two zones, one from the entrance to the tent - the vestibule (unheated and not requiring cooling) and the other, depending on the external conditions, heated or cooled. In these two zones, the external partitions are structurally different and therefore have different thermal insulation properties.

In the vestibule zone, only one layer of tent fabric was used, attached to the outside of the pneumatic frame. In the area of the heated and cooled tent, a fabric is attached to the frame on both sides, both from the outside and inside of the tent. As a result, the main thermal protection of the tent in the heated and cooled zone is a partition made of one outer fabric layer with a thickness of $0.30-0.35 \mathrm{~mm}$, an air gap of $220 \mathrm{~mm}$ and a second fabric layer of $0.30-0.35 \mathrm{~mm}$, forming the lining. In the gable wall of the tent, the air layer between the fabrics is $110 \mathrm{~mm}$ thick.

Depending on the order, small windows made of transparent PVC can be installed in the roof or wall of the tent.

The parameters of the external partitions of the tent were tested for two cases of climatic conditions, the cold period, with the temperature outside the tent $-30^{\circ} \mathrm{C}$ and the temperature difference between the heated zone and the external environment of $40 \mathrm{~K}$, and for the hot, summer period, with the external temperature of $50^{\circ} \mathrm{C}$ and the difference temperature $30 \mathrm{~K}$.

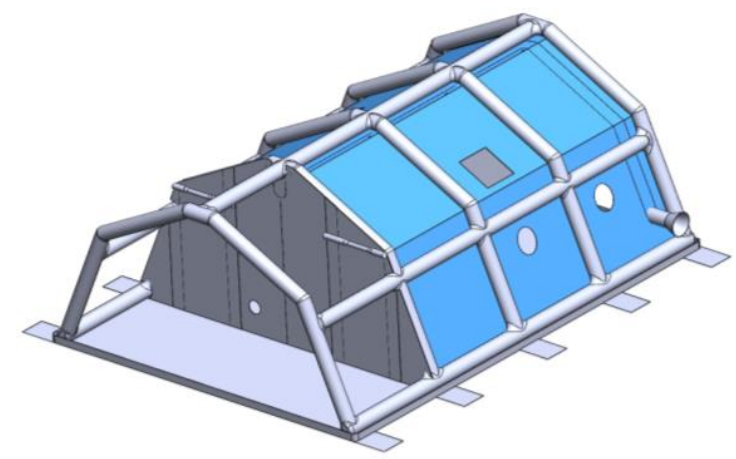

Fig. 1. Tent structure with a fabric layer forming a lining on the inside, with a distinguished vestibule zone and a heated or cooled zone; source (Lubawa S.A.)

\section{Laboratory tests of the thermal cover of the tent}

1. The thermal emissivity of the tent fabric surface was tested indirectly using the VarioCAM thermal imaging camera. On the other hand, the processing of measurement data from the camera was performed using the IRBIS re-mote 3.0 computer program. As a result of processing the measurement data, the average value of the emissivity of the tent fabric was determined, which was $\varepsilon=0.96$ for the green side (Fig. 2 a) and $\varepsilon=0.84$ for the gray side (Fig. 2 b). 

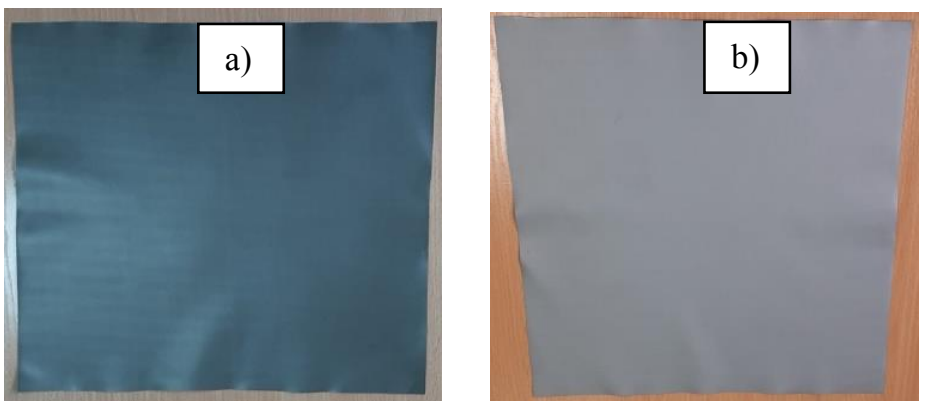

Fig. 2. Two different sides of the tent fabric, with the colours: a) dark green, b) gray; source (own photography)

2. The thermal conductivity of the fabric was tested on a test stand with the NETZSCH HFM 446 Lambda M lambda-meter. Due to the fact that the measuring instrument is used to test the thermal conductivity of material samples with a minimum thickness of $2 \mathrm{~cm}$, the measurements had to be performed indirectly. Lambda meter also measured the thickness of the tested samples. The measurements show that the average thickness of the samples of the material made available for testing was $0.31 \mathrm{~mm}$. Measurements made with the lambda meter show that the average thermal resistance of a single layer of fabric is $0.00351 \mathrm{~m}^{2} \cdot \mathrm{K} / \mathrm{W}$. This value was also used for further calculations of the thermal insulation properties of the walls and roof of the tent. Assuming the average thickness of the fabric samples at $0.31 \mathrm{~mm}$ and the average value of the thermal resistance of a single fabric layer of $0.00351 \mathrm{~m}^{2} \cdot \mathrm{K} / \mathrm{W}$, the average value of the tent fabric's thermal conductivity coefficient was $\lambda=0.088 \mathrm{~W} /(\mathrm{m} \cdot \mathrm{K})$.

\section{Determination of thermal insulation properties of the tent's thermal shield}

In accordance with the assumptions, the parameters of the tent's external partitions were calculated for two cases, the period of cold and hot summer. The calculations were made using the basic laws and dependencies describing heat transfer in building physics and the PN-EN ISO 6946 standard.

The values of heat transfer resistance on the inner $R_{s i}$ and outer $R_{s e}$ of tent enveplopes were determined, taking into account the emission properties of the surfaces of fabrics tent and foil on the windows (Table 1).

Table 1. Calculation results of the heat transfer resistance on the surfaces of the tent partition

\begin{tabular}{|c|c|c|}
\hline \multirow{2}{*}{$\begin{array}{c}\text { The surface of the outer } \\
\text { baffle }\end{array}$} & \multicolumn{2}{|c|}{ Resistance to heat transfer } \\
\cline { 2 - 3 } $\begin{array}{c}\text { and the color of the tent } \\
\text { fabric }\end{array}$ & \multicolumn{2}{|c|}{$\mathrm{m}^{2} \cdot \mathrm{K} / \mathrm{W}$} \\
\cline { 2 - 3 } & Cold period & $\mathrm{R}_{\mathrm{si}}$ \\
\hline wall - green & 0.134 & 0.125 \\
\hline wall - gray & 0.147 & 0.137 \\
\hline roof - green & 0.101 & 0.162 \\
\hline roof - gray & 0.107 & 0.182 \\
\hline window foil PVC in the wall & 0.136 & 0.127 \\
\hline window foil PVC in the roof & 0.102 & 0.165 \\
\hline \multicolumn{2}{|c|}{} \\
\hline \multicolumn{2}{|c|}{$\mathrm{R}_{\mathrm{se}}$} \\
\hline wall, roof - green & 0.0035 & 0.032 \\
\hline
\end{tabular}


Due to the fact that their calculations took into account the temperature conditions of the partition's operation and their emission properties, they were used for further calculations.

Table 2 shows the values of the thermal resistance of the air layers $R_{a l}$ in the individual partitions of the tent for the cold and hot period.

Table 2. Calculation results of the heat transfer resistance on the surfaces of the tent partition

\begin{tabular}{|c|c|c|}
\hline \multirow{2}{*}{$\begin{array}{c}\text { Air layer in the outer } \\
\text { partition }\end{array}$} & \multicolumn{2}{|c|}{ Resistance to heat transfer, $\mathrm{R}_{\mathrm{al}}$} \\
\cline { 2 - 3 } & Cold period & Hot period \\
\cline { 2 - 3 } & \multicolumn{2}{|c|}{$\mathrm{m}^{2} \cdot \mathrm{K} / \mathrm{W}$} \\
\hline in the wall & 0.182 & 0.141 \\
\hline in the roof & 0.145 & 0.123 \\
\hline window in the wall & 0.162 & 0.123 \\
\hline window in the roof & 0.132 & 0.109 \\
\hline
\end{tabular}

Then the values of the thermal resistance $R_{\text {tot }}$ and the heat transfer coefficient $U$ of the external envelopes of the tent were determined. The calculations were made for the case of tent heating during cold winter and cooling during hot summer (Table 3 ).

Table 3. Results of calculations of thermal resistance $R_{\text {tot }}$ and heat transfer coefficient $U$, external partitions of the tent

\begin{tabular}{|c|c|c|c|c|}
\hline \multirow{3}{*}{ External partitions } & \multicolumn{2}{|c|}{ Thermal resistance, $\mathrm{R}_{\text {tot }}$} & \multicolumn{2}{|c|}{ Heat transfer coefficient, U } \\
\hline & $\begin{array}{c}\text { Cold } \\
\text { period }\end{array}$ & Hot period & $\begin{array}{c}\text { Cold } \\
\text { period }\end{array}$ & Hot period \\
\hline & \multicolumn{2}{|c|}{$\mathrm{m}^{2} \cdot \mathrm{K} / \mathrm{W}$} & \multicolumn{2}{|c|}{$\mathrm{W} /\left(\mathrm{m}^{2} \cdot \mathrm{K}\right)$} \\
\hline wall & 0.373 & 0.317 & 2.681 & 3.154 \\
\hline roof & 0.296 & 0.344 & 3.378 & 2.907 \\
\hline window in the wall & 0.338 & 0.285 & 2.963 & 3.515 \\
\hline window in the roof & 0.274 & 0.308 & 3.656 & 3.241 \\
\hline
\end{tabular}

The determined values are necessary to determine the heat demand in the tent's operating conditions, in a cold climate, and the energy demand for cooling, in a hot climate. If the tent is used in hot climates, they are also needed to determine the Envelope Thermal Transfer Value (ETTV) and the Roof Thermal Transfer Value (RTTV).

\section{Conclusion}

As a result of the research, the parameters of the thermal protection of the tent used in extremely unfavorable climatic conditions, in a cold and hot climate, were established. The values of the thermal emissivity factor $\varepsilon$ of the tent fabric on both sides were determined. This factor has a significant impact on the value of the heat transfer coefficient of the tent casing. For the dark green surface, the obtained value was $\varepsilon=0.96$, and for the gray side, $\varepsilon=$ 0.84 . In the thermal conductivity tests carried out on the lambda-meter, the average value of the thermal conductivity coefficient $\lambda$ of the tent fabric was $0.088 \mathrm{~W} /(\mathrm{m} \mathrm{K})$. The values of thermal resistance of air layers in tent partitions (wall, roof, window) were determined separately for the cold and hot period. The obtained test results indicate the significant importance of the thermal emissivity parameters of the tent fabric on the thermal insulation 
value of tent partitions. Significant differences were found in the thermal insulation parameters of individual external partitions in cold and hot climate conditions. The obtained results can be used to select heating and air-conditioning devices and to create thermal comfort conditions in tents operated in various climatic zones.

\section{References}

1. K. Cena, N. Davey, T. Erlandson, Applied Ergonomics 34, 543-550 (2003). phttp://dx.doi.org/10.1016/S0003-6870(03)00084-X

2. R. Pöschl, Loughborough's Research Repository 2016, https://hdl.handle.net/2134/25131

3. M. Dabaieh, A. Borham, Acclimatization measures for temporary refugee shelters in hot arid climates; low-tech mobile solutions using bedouin tents. In M. Cucinella, G. Pentella, A. Fagnani, L. D'Ambrosio (Eds.), 2015

4. R. Potangaroa, M. Hynds. Thermal Comfort Tools for Emergency Shelter in Major Disasters. Proceedings from International Conference on Building Education and Research (BEAR), School of the Built Environment, University of Salford, UK, 2008, p.1457-1472, http://www.irbnet.de/daten/iconda/CIB11441.pdf

5. H Gooijer, M. Velan, I. Esen, S. Kamphuis, R. Groeneveld, P. Agrawal, G. Brinks, Thermal comfort of textiles for tent application. AUTEX2019 - 19th World Textile Conference on Textiles at the Crossroads, 11-15 June 2019, Ghent, Belgium

6. L. Zhang, Y. Yu, L. Xu, W. Zhang, Q. Shen, International Journal of Low-Carbon Technologies 12, 36-42 (2017). https://doi.org/10.1093/ijlct/ctw005

7. T. Stegmaier, J. Sarsour, G.T. Gresser, R. Wagner, B. Kröplin, P. Kungl, A. Kneer, W. Arnold, H. Bögner-Balz, Innovative Energy \& Research 7 (3), 218 (2018). https://doi.org/10.4172/2576-1463.1000218

8. J. Liu, Y. Jiang, Z. Gong, H. Yang, J. MATEC Web of Conferences 61, (2016). http://dx.doi.org/10.1051/matecconf/20166101009

9. S.W. Lee, C.H. Lim, E.I. Salleh, Renewable and Sustainable Energy 61, 01009, pp. 643-661. (2016). http://dx.doi.org/10.1016/j.rser.2016.07.002

10. L. Zhang, X. Menga, F. Liua, L. Xub, E. Long, Case Studies in Thermal Engineering 9, 122-127 (2017). http://dx.doi.org/10.1016/j.csite.2017.02.001

11. A. Ujma, N. Umnyakova, E3S Web of Conferences 100, 2019. DOI: https://doi.org/10.1051/e3sconf/201910000082

12. J. Jura, Construction of optimized energy potential 2, 39-44 (2015).

13. G. Harvie, Thermal behaviour of architectural fabric structures. Website https://www.designingbuildings.co.uk/w/index.php?title=\%3AThermal_behaviour_of_ architectural_fabric_structures\&action=edit

14. D. P. Ayu, B. Prayitno, A. Hariyadi, ASEAN Journal on Science \& Technology for Development 36, 3, 91-96 (2019). http://dx.doi.org/10.29037/ajstd.582

15. A. Alekseeva, Yu Tanacheva, M. Ushakov, International Multi-Conference on Industrial Engineering and Modern technologies, IOP Conf. Series: Materials Science and Engineering $\mathbf{0 2 2 0 2 0}$ (2018). IOP Publishing, http://dx.doi.org/10.1088/1757-899X/463/2/022020 